\title{
PLOTINO Y EL PROBLEMA DE LAS ESTRELLAS: UNA SOLUCIÓN PARA LOS NEOPLATÓNICOS'
}

\author{
Luis Miguel de Vicente García \\ Universidad Autónoma de Madrid
}

\section{RESUMEN}

La lectura plotiniana de la sincronicidad entre astros y hechos humanos en vez de la lectura causa-efecto de la astrología judiciaria tradicional fue la visión más seguida por el humanismo. Las estrellas no representan poderes en si mismos sino como símbolos o signos. El hombre sabio, y así lo entendieron también los humanistas neoplatóncios, es aquél que sabe interpretar los símbolos desentrañando el sentido de la simpatía o analogía universales. El poder simbólico, por basarse en una inspiración abierta más que en el raciocinio lógico, entronca con otros lenguajes simbólicos, incluido el de la literatura, al que presta numerosos recursos.

Palabras clave: Plotino, sabio, estrellas, simbolismo, analogía universal.

\begin{abstract}
The Plotinian way of reading the relationship between stars and human issues as a matter of synchronicity rather than the traditional cause-effect relationship proposed by Astrology was followed by the humanists in general. The symbolic power of signs is based on inspiration more than on rational discourse, and it can be related by wise men to other symbolic languages, including literature, with which it shares many devices. The wise man, according to the Neoplatonic humanists, knows how to interpret the symbols, how to read one thing in another, uncovering the meaning of universal analogy.
\end{abstract}

Key words: Plotinus, stars, symbolisum, universal analogy.

Fue el pensamiento pagano el responsable de desarrollar tanto las observaciones como las reflexiones filosóficas sobre el problema de las estrellas; sus respuestas son el precedente y la inspiración de los pensadores cristianos, que las adaptaron a modificaron conforme a su visión del mundo, mediatizada por la necesidad de hacer compatibles fe y razón. Como ocurre al rastrear los

1 Quiero agradecer a la Fundación Caja Madrid la concesión de una Beca de investigación postdoctoral que me ha permitido llevar a cabo este trabajo. 
fundamentos de la civilización occidental, las ideas de Platón y Aristóteles son el punto de partida sobre el que se desarrollaron la mayor parte de las concepciones del mundo. La asimilación de las teorías físicas aristotélicas por parte de la Iglesia es un fenómeno sobre todo del siglo XIII, con la Escolástica. En cambio el neoplatonismo, al descartar la relación de causalidad entre las estrellas y la vida humana, preparaba el camino a la solución cristiana. Las teorías de Plotino sobre el problema de los astros están en la base de todo el pensamiento medieval y merece por tanto un estudio detenido.

Plotino enseña intentando sintetizar las diveras corrientes del pensamiento antiguo, incluida la astrología. Está influido por el neopitagorismo, la filosofía griega, la filosofía romana y las diversas creencias religiosas y místicas, entre ellas la tradición de los libros de Hermes. ${ }^{2}$ Ante todo, Plotino se considera el heredero de la tradición platónica; en sus obras comenta, incorpora y critica el pensamiento de Platón y Aristóteles, con preferencia por el primero. Junto con San Agustín y el PseudoDionisio, Plotino determina el pensamiento de la Edad Media. La segunda Eneada de Plotino se dedica enteramente al problema de las estrellas. Vistos como partes del todo, los cuerpos celestes no pueden ser para este filósofo una realidad distinta cualitativamente de los cuerpos terrestres, como habían sostenido tanto platónicos como aristotélicos (Eneada 2 libro 1 capítulo1) ${ }^{3}$ El filósofo alejandrino unifica enormente la división tradicional entre el mundo sublunar y el supralunar. Tanto para Platón como para Heráclito los cuerpos celestes también están sometidos al flujo o al cambio de la materia (2 12 ). Para Aristóteles el problema se solucionaba aceptando que los cuerpos celestes estaban constituidos de una quinta esencia, distinta de la de los cuerpos terrestres, que no era afectada por los cambios del mundo sublunar. Pero Plotino nos dice que para los que no aceptaban la teoría de la quinta esencia aristotélica -él entre ellos- era muy difícil probar racionalmente cómo podía mantenerse perpetuamente la individualidad de los cuerpos celestes si estuvieran sometidos a la transformación de la materia. Para Plotino el problema radica en determinar cómo la materia que está sometida a continuo flujo $-\mathrm{y}$ que forma físicamente el mundo- puede contribuir a la inmortalidad del cosmos (2 13$).{ }^{4}$ Su respuesta es, como en el caso de Orígenes, que la materia no se pierde, sino que sólo se mueve y se transforma. ${ }^{5}$ Plotino pone el ejemplo de la vida en la tierra, donde nunca se acaba ni el aire ni el agua. En la tierra los cuatro elementos tienden a ocupar su lugar -el fuego, como el humo, tiende a ascender y la tierra a permanecer; ningún elemento se pierde porque el circuito del alma previene toda destrucción (2 13 3). Es el alma lo que para Plotino mantiene la unidad y la permanencia del cosmos y la responsable de la inmortalidad del sistema celeste, independientemente de las características de la materia que, en el caso de los cuerpos celestes, debe ser más noble que la que experimentamos en el mundo sublunar $(214){ }^{6}$ Para justi-

2 Cf. Robert Amadou p.13.

3 En lo sucesivo cito a Plotino por Eneada, libro y capítulo consignando solo los números correspondientes a cada uno de esos apartados separados por un espacio: 213.

4 «Quo igitur modo materia corpusque universi ad immortalitatem mundi conducet, cum perpetuo fluat?» (p.52).

5 «Si igitur in se ipso, non autem a se ipso fluit, nimirum permanens idem, nec augetur neque minuitur: neque igitur consenescit» (p.52).

6 Plotino está de acuerdo con Aristóteles en ver en el fuego la característica material más excelente que compone los cuerpos celestes, pero no como una llama en forma de torbellino, sino como un fuego plácido que cumple el propósito de las estrellas. Los elementos pueden estar en cambio perpetuo, pero el alma permanece sin cambio, y justifica la existencia eterna del cosmos (2 l 4 ). 
ficar cómo puede haber permanencia en el mundo si las partes del todo y de la esfera celeste están sometidas a cambio, se apoya en Platón, que justificaba el orden celeste como emanación de Dios (2 15 ). ${ }^{7}$ El alma, al encarnarse en la esfera inferior o mundo sublunar, toma substancias que no son imperecederas. Plotino se pregunta a continuación por la materia que compone los cuerpos celestes y recuerda lo que Platón había establecido en el Timeo: la materia del todo se componía de fuego y tierra -el fuego para la visibilidad, porque causa la luz, y la tierra para la solidez-, y deducía que la estrellas debían estar compuestas sobre todo de fuego, pero también de tierra, ya que se nos presentan como sólidas. Aunque Plotino básicamente acepta lo que Platón escribe en el Timeo, mantiene también que los cuatro elementos deben tener una cierta interacción con los elementos que componen la materia celeste, en una especie de préstamo mutuo o «co-operación cósmica» (2 17 ). La idea de la unidad del mundo radica en su concepción del alma como una entidad capaz de dar unidad a todo, puesto que el movimiento del alma es hacia sí misma, un movimiento de autoconciencia (2 2 1). La naturaleza del fuego celeste hace que los cuerpos se muevan de un modo circular hasta que cumplen su destino, ya que la naturaleza del fuego es moverse en curva, pues si se moviera en una línea, se saldría del universo. Pero el centro de un círculo - y el del cosmos-es un punto de descanso. Por eso se explica el circuito de los cielos; el alma ocupa el centro del movimiento, permaneciendo inmóvil. Pero esto no ocurre exactamente así en el mundo sublunar debido a la diferencia entre cuerpo y alma: el centro para el cuerpo es un punto, mientras que para el alma es una fuente de otra naturaleza. El alma existe en torno a Dios, movida por el amor, y lo rodea en círculo porque no puede identificarse con él (22), mientras el cuerpo, que no sigue un movimiento circular, se mueve en el espacio. El Principio-Intelectual que alienta todo movimiento no tiene localización espacial sino que gira en torno a sí mismo y al tiempo no se mueve.

Respecto al tema de las estrellas como causa de los destinos humanos, Plotino se enfrenta a las creencias comunes de su tiempo, según las cuales el curso de los planetas determina el destino de un individuo: su pobreza o riqueza, enfermedad, vicio o virtud, etc. Para Plotino estas ideas no tienen fundamento, y menos aún el que se atribuya a unos planetas el ser malignos y a otros el ser benignos', o que se diga que cambian su influencia según la posición que tengan en las casas y los signos zodiacales o según la relación geométrica que guardan entre sí los planetas - lo que se llama aspectos zodiacales. La primera pregunta que se hace el filósofo alejandrino para rebatir tales creencias es si los planetas tienen o no alma. Si no la tienen, cualquier emanación de ellos afectará sólo a nuestra naturaleza física pero no a la anímica (2 3 2). Además, si eso es así, la influencia corporal que pudieran causar no diferiría mucho de planeta a planeta, puesto que nada espiritual les da el poder de una determinada influencia en vez de otra. Así pues, si los astros son objetos físicos, Plotino no ve la razón por la que éstos podrían causar la riqueza o la pobreza de un hombre, por ejemplo. $\mathrm{Si}$, por el contrario, suponemos que los planetas tienen vida y mente, la pregunta de Plotino es entonces: ¿qué le han hecho los hombres a los planetas para que éstos los castiguen ocasionándoles daños; teniendo en cuenta que los planetas están en un lugar privilegiado donde los hombres no pueden causarles ningún mal a ellos? (2 3 3). Su conclusión es, como repetirán constantemente

7 Dice Plotino: "At curnam partes in caelo consistunt, elementa vero apud nos et animalia minime? Forsan, ut inquit Plato, propterea, quod illa quidem ab ipso deo sunt facta, sed haec apud nos animalia a diis deo genitis sunt effecta: facta vero ab ipso deo nefas est interire" (p.53) 
los pensadores cristianos, que los astros no tienen vida ni mente y que, por tanto, no hay nada en su naturaleza que pueda ejercer maldad o bondad sobre los hombres (2 3 3). Como hará San Agustín después, Plotino critica la subjetividad de los levantadores de horóscopos ya que un planeta, considerado en sí mismo, es el centro en relación a otro y está en decadencia con relación a otro distinto. No tiene sentido, pues, decir de un mismo planeta que a veces es triste y a veces alegre: no hay razón para representar a los planetas alegres en su puesta y a otros en su salida, porque eso emana sólo de la perspectiva del observador y no de los planetas en sí mismos (2 3 3). Este relativizar las nociones astrológicas a favor de su dimensión simbólica es lo que le permite a Plotino reinterpretar. el valor connotativo de entidades como Saturno, tradicionalmente identificado con la infortuna y el maleficio. Domingo Yndurain comenta a propósito: "Plotino da la vuelta al lugar de Plinio en que se describe la miseria de la condición humana: el hombre no tiene menos medios que los animales los que carecen de lo necesario para su conservación,y, por ello, ha sido necesario concederles alguna ayuda. Es un cambio de perspectiva semejante al que el mismo Plotino realiza a propósito de Saturno que, de ser una fuerza destructora, negativa, pasa a convertirse en un principio benéfico, una influencia regeneradora, lo que facilita que Ficino lo convierta en patrono de los hombres de letras, despojando de tal función a Mercurio o a Hermes". ${ }^{8}$ Se trata en realidad de incorporar, con la libertad que da el lenguaje simbólico, las connotaciones mitológicas asociadas a Saturno (dios del tiempo, que representa el esfuerzo y la disciplina asociadas al estudio, así como la superación de las pasiones que es la clave del éxito del sabio humanista y que se consigue tras el paso de la juventud a la madurez-ancianidad, simbolizadas por Saturno). El lenguaje astrológico empieza a tener la misma libertad que el lenguaje literario y Plotino es tal vez quien mejor brinda a los humanistas esta libertad simbólica, liberada del más rígido lenguaje de la astrología judiciaria que está más ligada a las matemáticas y, por tanto, tiende a construir un lenguaje más unívoco donde Saturno simbolizaba obstáculos, infortuna, etc en una serie de relaciones aspectuales con el resto de entidades astrolgócias (otros plantetas, casa, signos etc.) Para Plotino los astros pueden servir incidentalmente para predecir el futuro en virtud de la analogía que se da entre las distintas partes del universo, pero no están puestos para ese fin. ${ }^{9}$ En ese sentido el filósofo iguala la astrología con otras formas de adivinación, como la que se hace a través de la aves (2 33 ). En cierto modo, esta solución se aproxima

\section{Domingo Ynduráin. Humanismo y Renacimiento en España. Madrid: Catedra, 1994, p.278}

9 En palabras acertadas de Ynduráin: "Estos símbolos, que funcionan como carismas, cumplen su efecto aunque su mecanismo no se haga consciente [...] Todo lo cual, en definitiva, y si se elimina el carácter sacramental, coincide con el concepto habitual de símbolo en la literatura (op. cti. p.268) Aunque es fundamental precisar que estos símbolos son parte de la inspiración divina que puede encarnar un sabio y no de una mera creatividad gratuita. Cualquier áspecto de la creación que traduzca el plan divino puede servir de referencia para una interpretación acertada de los hechos y de los sentidos ocultos de los hechos. No se consigue esto aplicando una fórmula infalible sino a través de la conexión con la inspiración divina, así logra el sabio saber leer por analogía las similitudes entre las partes del todo, que espejan, como el átomo, las características de todo el universo. La esencia divina es una e inefable para el lenguaje convencional y sólo sugerible para el lenguaje simbólico. La esencia misma está protegida por un velo para el conocimiento en el que insiten los humanistas tanto como otros buscadores de la Verdad (véase la Epístola de Aldana para Arias Montono o la descripción de Severo en la Egloga segunda de Garcilaso, entre otros muchos poemas donde los humanistas expresan su noción de sabio y la relación del hombre con el conocimiento) Los símbolos tanto para Plotino como para los humanistas neoplatónicos dan cuenta o traducen la presencia de un plan de Dios del que habla tanto la geometría, la aritmética, los sonidos, la música, la medicina y el mismo silencio. No es un plan que se pueda comprender sin la ayuda de la analogía ente las distintas partes del universo y su conocimiento escapa a las limitaciones del lenguaje convencional y adopta la metáfora y el símbolo (la poesía entre los humansitas) como vehículo de sugerencia más que de definición. 
bastante a la que dará San Agustín, para quien, como veremos, el astrólogo puede acertar por suerte, en sus predicciones del futuro. ${ }^{10}$ Plotino critica sobre todo los aspectos mitológicos y antropomórficos con que se representa a los planetas, así como la arbitrariedad de los aspectos planetarios. No hay causa de enemistad entre los planetas para que los astrólogos los representen formando entre sí relaciones favorables o desfavorables para los hombres (2 3 5). Plotino, al igual que San Agustín, conoce muy bien el lenguaje astrológico, alude con frecuencia al significado de las conjunciones de la Luna con otros planetas o a otros aspectos planetarios cuyo conocimiento y uso pertenecía al dominio de la astrología. ${ }^{11}$

La función de las estrellas para Plotino es servir al propósito común del universo; los astros no funcionan como poderes en sí mismos sino como símbolos o signos. De ese modo el hombre sabio es aquél que sabe interpretar los símbolos, o sea, aquél que puede leer una cosa en otra desentrañando el sentido de la simpatía o analogía universales; las estrellas son, pues, una especie de lenguaje simbólico, como establece en la Eneada 2, libro 3, capítulo 7:

Sint igitur tanquam literae in caelo, quae vel scribantur assidue vel jam conscriptae perpetuo explicentur, aliud quiddam opus efficientes: unde significatio rerum ab ipsis facta sequatur: quemadmodum in uno vivente ab uno principio ab alio membro aliud judicare quis potest [...] Plena vero omnia sunt signorum, et sapiens aliquis aliud argumentatur ex alio. Multa quin etiam quotidie consueta nota sunt omnibus (p.64).

En suma, la astrología para Plotino, en cuanto que trata sobre los poderes de los planetas, es una ciencia separatista que afecta a la unidad del universo, el cual está regido por un solo principio que opera en cada miembro de la creación de arriba a abajo. Si bien el filósofo alejandrino considera que la astrología carece de rigor, ${ }^{12}$ los planetas en sí significan la existencia de un orden supe-

10 Sin embargo una diferencia fundamental distingue las meditaciones sobre la astrología en Plotino y en los autores cristianos posteriores: Plotino, que no pretende justificar ni defender una fe establecida por ninguna revelación en concreto, se esfuerza por comprender, no por condenar, a la astrología y los demás intentos humanos por predecir el futuro. Como Amadou ha visto bien, « il [Plotino] a su prêter un sens acceptable à la magie, au destin, à l'astrologie, à la théurgie» (20). La crítica de Plotino a la astrología es una crítica constructiva: «La critique de Plotin [...] est loin d'être toute négative. C'est la critique d'une certaine conception de l'astrologie,[...] du destin et de la liberté, ou de l'absence de liberté plutôt et de la fatalité, résultant d'une cosmologie, d'une anthropologie et d'une théologie fausses» (p.31).

11 Su alumno y editor, Porfirio, nos relata cómo comienza a criticar los horóscopos, en parte como en el caso de San Agustín, después de estar familiarizado con ellos: "Il accorda quelque attention aux principes de l'astronomie, mais ne poussa pas très loin l'étude mathématique du sujet. Il approfondit davantage l'horoscopie. Quand il finit par être convaincu qu' on ne pouvait se fier à ses résultats, il n'hésita pas à attaquer fréquemment le système à la fois dans ses cours et dans ses écrits." (15 16; Apud Amadou p.20). El ataque a la astrología en Plotino se centra, como estamos viendo, sobre todo en los aspectos arbitrarios o antropomórficos del levantamiento de horóscopos, no contra la «astrología semántica» o simbólica que puede ver en las estrellas símbolos de la ordenación y belleza del todo. Más duros son los ataques a la astrología en Cicerón, Favonio, Sexto Empirico o del griego Luciano de Samosata, un poco anterior a Plotino (cf. Amadou, p.21).

12 Al parecer de Amadou, los astrólogos a los que se refiere Plotino son los gnósticos, en especial a Marco Manilio, autor, durante el reinado de Augusto, del tratado de astrología más antiguo conocido, la Astronomica. Plotino reprocha a los astrólogos su fatalismo y su panteísmo; estas dos características se apoyan en la cosmología de los estoicos y el determinismo de Crisipo; también los ataques de Plotino irían dirigidos, al parecer de Amadou, contra el sistema de Ptolomeo, o sea, contra la astrología judiciaria (Amadou op. cit. p.21) En cuanto a sus ideas astrológicas, según Amadou, Plotino sigue a Filón de Alejandría, judío que combina el platonismo y la revelación, y para quien los astros no son causas primeras como pretendían los caldeos (p.29) 
rior, material y espriritual, y como parte del todo, son una fuente de conocimiento del principio o causa primera que alienta toda la vida. La base de toda adivinación está en conocer el principio de la coordinación de las partes del universo; tal principio funcionaría no sólo con las estrellas sino con cualquier otro elemento del cosmos, ya que todo es una cadena, y por simpatía y correspondencia, lo que se encuentra en un organismo debe encontrarse también en otros, en forma más intensa según se asciende en la cadena o jerarquía de las partes del todo (2 3 7). Para Plotino la cadena del universo es tan perfecta que no hay nada regido por azar $(237) .{ }^{13}$ En esa cadena de la creación, las estrellas son co-operadores que contribuyen a establecer la belleza del universo con su cualidad simbólica. Su poder simbólico es inmenso, pero su poder efectivo se reduce a ser lo que son y a hacer lo que manifiestamente hacen como cuerpos del universo $(238) .{ }^{14}$ Esa es sin duda la definición de las estrellas que más afectará a las generaciones de neoplatónicos que, como Marsilio Ficino, verán en las estrellas no causas del destino humano sino símbolos en los que se puede leer la belleza del cosmos. La riqueza y la pobreza no son ocasionadas por las estrellas, sino por factores externos que nos afectan en el mundo de la multiplicidad que vivimos como consecuencia de nuestra caída en el mundo de la materia. La virtud es causada por el alma, y el vicio por nuestro comercio con el mundo de afuera (2 3 9). Plotino comenta la teoría de la necesidad tal y como se expresaba en el Timeo: Dios crea el alma, pero las divinidades que se mueven en el cosmos - las estrellas - infunden las inclinaciones que emanan de la necesidad, impulsos y deseos, dolor o placer, y toda la experiencia más baja del alma. Si nos movemos bajo necesidad desde el momento que entramos en el mundo, nuestro temperamento está ligado al orden de las estrellas, y las acciones derivarán del temperamento. Pero para Plotino el hombre tiene el poder de gobernar su propia naturaleza porque Dios ha dotado al ser humano, en medio de todo el mal, de virtud con la que podrá liberarse de la esfera material, como escribe en la segunda Eneada, libro 3, capítulo 9:

"Fortasse vero reliquum est, quod ipsi re vera sumus: quibus et natura dedit, ut passionibus dominari possemus. Etenim praeter id, quod ob ipsam naturam corporis his malis circumventi sumus, deus virtutem largitus est a servitute penitus liberam. Non enim virtute nobis opus est in tuto quodam statu positis, sed quando absente virtute discrimen in malis imminet. Quam ob rem fugere hinc oportet, nosque ipsos ab his, quae in generatione adjuncta nobis sunt, segregare." (p.65).

Esa conclusión de Plotino sienta las bases de lo que serán luego las respuestas de los Santos Padres a la cuestión de las estrellas: contra el hombre virtuoso ningún poder tienen las estrellas: «Sol quin etiam atque cetera similiter duplicia sunt. Et alteri quidem animae, quae pura est, pravi aut vilis nihil afferunt» (p.66).

13 He aquí el texto latino: "Nihil enim usquam ab ipsa totius forma sejungitur: aguntque invicem atque patiuntur, et accedit ad quodlibet aliquid, quod vel offendat vel adjuvet. Procedunt autem non temere neque utcunque contingit: etenim aliud quiddam ex his efficitur, aliudque naturaliter deinceps aliudque consequitur:" (p.64).

14 Plotino escribe: "Quodsi aliorsum adducta praevaricetur, judicio quodam cursum eorum sequitur, quae efficiuntur in mundo, nisi forte solvatur. Permanet enim judicium ipsum semper: quippe cum universum ordine potentiaque dominantis regatur atque dirigatur. Serviunt huic conferuntque stellae, ceu partes caeli non parvae: tum ad decoram totius formam, etiam ad significationis officium: portendunt itaque omnia, quaecumque in mundo sensibili oriuntur; faciunt vero alia quaecumque faciunt manifeste." (p.65). 
Sin embargo, alguna influencia - aunque no de causalidad — ha de concederse a los astros sobre los hombres en general. ${ }^{15}$ El momento en el que el alma entra en el cuerpo está determinado, nos dice Plotino, por el circuito cósmico, y, por tanto, hay que admitir algún poder efectivo de los planetas en ese circuito, un poder co-operativo que completa la tarea del todo (2 39 ). Las virtudes del espíritu se deterioran al entrar en contacto con el mundo de la materia. Las estrellas no son las responsables de la formación del ser humano, aunque el Sol cumpla su función en el desarrollo físico del hombre, como lo aceptan en general los Santos Padres desde San Ambrosio a San Isidoro. El hombre tiene su origen, sin embargo, en el Principio-humano (2 3 8). En ese sentido los planetas, como otros factores externos, afectan a la formanción del hombre pero no lo constituyen como tal. Las partes del todo que carecen de alma son sólo instrumentos; eso son las estrellas, instrumentos del universo de un lado, y símbolos de su belleza de otro. En suma, Plotino pretende asimilar la astrología a la filosofía, dejarla como competencia del hombre sabio, desproveerla de leyes fatalistas y conservarla en cuanto a su sentido simbólico, que habla de la unidad y la belleza universales. El hombre sabio, en cuanto que llega a conocerse a sí mismo, puede interpretar los símbolos contenidos en las diversas partes de la creación, que no está regida ni dividida por dos principios opuestos, Bien y Mal, sino por un propósito único que tiende hacia Dios, hacia el sumo Bien, en un movimiento circular, pues le tiene a El por centro. La astrología debe ser más que geocéntrica -lo cual es muy subjetivo y parcial para Plotino- teocéntrica, ya que sus símbolos - los astros- hablan del Principio rector del todo. El alma es la verdadera intérprete y el verdadero centro del astrólogo según el filósofo alejandrino, pues en ella cobran sentido las diferentes partes de la creación. Con esta visión, Plotino se constituye en una fuente riquísima de soluciones para los pensadores cristianos posteriores, cuyas reflexiones sobre la astrología estarán, no obstante, sazonadas de ataques menos constructivos que los del filósofo alejandrino, pues partirán de un enfrentamiento dialéctico -asumido a priori- entre fe y astrología. ${ }^{16}$

\author{
Luis Miguel de Vicente García \\ Universidad Autónoma de Madrid \\ Departamento de Filología Hispánica \\ Cantoblanco \\ 28049 Madrid
}

15 Por ejemplo, las estrellas, nos dice Plotino, pueden anunciar — no causar - la pobreza o la riqueza de alguien; cuando esta riqueza se hereda o se consigue mediante la actividad del individuo entonces entran en juego poderes físicos que se deben en parte a los padres, en parte a la influencia de los planetas y de la tierra, ya que se trata de un aspecto físico que está bajo el influjo del mundo supralunar, pero también la buena fortuna puede deberse al ejercicio de la virtud $(23$ 14). Si, por el contrario, la fortuna se adquiere por el ejercicio de la maldad, se debe a la maldad misma y a un mal uso de los poderes físicos que, por sí mismos, no causan una acción u otra. La riqueza puede también ganarse por trabajo o esfuerzo, o por la suerte de encontrar un tesoro, por ejemplo, para lo cual entra en juego algo de la cadena de sucesos universales que pueden ser previstos por el sabio que sepa verlos (2 3 14).

16 Para Plotino Dios es todavía una Inteligencia ordenadora, tal como se establecía en el Timeo. Para los pensadores cristianos, en cambio, la divinidad era concebida en términos de una Voluntad creadora; Anderson expresa esta diferencia con precisión: «The concept of the ordering Intelligence as a willing Intelligence, rather than a passively expressive one, was characteristic of the Judaeo-Christian tradition [...] For those among the Church Fathers who considered the problem, the only «law of nature» was the will of an omnipotent God [...] In neither case would the patterns through which creation functioned in daily phenomena become particularly interesting. Man's relationship with God and man's capacity [...] for attaining salvation concerned the Church Fathers, not the timing of tides or the source of winds» (pp.8-9) 


\section{OBRAS CITADAS}

Amadou, Robert. «Le Message astrologique de Plotin.»L'Astrologie. Cahiers De l'Hermétisme. Paris: Albin Michel, 1985. 13-49.

Anderson, Carol Susan. Divine Governance, Miracles and Laws of Nature in the Early Middle Ages: The <De mirabilibus Sacrae Scripturae>. Tesis doctoral. Los Angeles: University of California, Los Angeles, 1982.

Plotini. Enneades. Cum Marsilii Ficinii Interpretatione Castigata. Parisis: Editore Ambrosio Firmin Didot, 1855.

Ynduráin, Domingo Humanismo y Renacimiento en España. Madrid: Catedra, 1994. 